\title{
The role of education in selection and allocation on the labour market; an empirical study in the medical field
}

\author{
Citation for published version (APA):
}

Semeijn, J. H., van der Velden, R. K. W., Heijke, J. A. M., van der Vleuten, C. P. M., \& Boshuizen, H. C. (2004). The role of education in selection and allocation on the labour market; an empirical study in the medical field. Researchcentrum voor Onderwijs en Arbeidsmarkt, Faculteit der Economische Wetenschappen. ROA Research Memoranda No. 1E https://doi.org/10.26481/umaror.200401E

Document status and date:

Published: 01/01/2004

DOI:

10.26481/umaror.200401E

Document Version:

Publisher's PDF, also known as Version of record

\section{Please check the document version of this publication:}

- A submitted manuscript is the version of the article upon submission and before peer-review. There can be important differences between the submitted version and the official published version of record. People interested in the research are advised to contact the author for the final version of the publication, or visit the DOI to the publisher's website.

- The final author version and the galley proof are versions of the publication after peer review.

- The final published version features the final layout of the paper including the volume, issue and page numbers.

Link to publication

\footnotetext{
General rights rights.

- You may freely distribute the URL identifying the publication in the public portal. please follow below link for the End User Agreement:

www.umlib.nl/taverne-license

Take down policy

If you believe that this document breaches copyright please contact us at:

repository@maastrichtuniversity.nl

providing details and we will investigate your claim.
}

Copyright and moral rights for the publications made accessible in the public portal are retained by the authors and/or other copyright owners and it is a condition of accessing publications that users recognise and abide by the legal requirements associated with these

- Users may download and print one copy of any publication from the public portal for the purpose of private study or research.

- You may not further distribute the material or use it for any profit-making activity or commercial gain

If the publication is distributed under the terms of Article $25 \mathrm{fa}$ of the Dutch Copyright Act, indicated by the "Taverne" license above, 
The role of education in selection and allocation on the labour market; An empirical study in the medical field

\author{
ROA-RM-2004/1E \\ Judith Semeijn*, Rolf van der Velden*, Hans Heijke*, \\ Cees van der Vleuten** Els Boshuizen***
}

* Research Centre for Education and the Labour market (ROA). Faculty of Economics and Business Administration, Maastricht University, The Netherlands

** Faculty of Medicine, Department of Educational Development and Research, Maastricht University, The Netherlands

*** Educational Technology Expertise Centre (OTEC), Open Universiteit Nederland, Heerlen, The Netherlands

\title{
Research Centre for Education and the Labour Market
}

Faculty of Economics and Business Administration

Maastricht University

Maastricht, January 2004 
ISBN 90-5321-385-6

Sec04.005 


\section{Contents}

1 Introduction and Problem Statement 1

2 Theoretical background 3

3 Data and methodology $\quad 7$

4 Results 10

5 Conclusion and Discussion 21

$\begin{array}{ll}\text { References } & 24\end{array}$

$\begin{array}{ll}\text { Appendix } 1 & 26\end{array}$

$\begin{array}{ll}\text { Appendix } 2 & 28\end{array}$

$\begin{array}{lr}\text { Appendix } 3 & 30\end{array}$

$\begin{array}{ll}\text { Appendix } 4 & 31\end{array}$ 



\begin{abstract}
In this study, we explore the role of education in explaining the labour market outcomes for graduates in medicine. More specifically, we focus on the question: To what extent are labour market outcomes of physicians explained by the skills acquired in education, as argued in the theory of Human Capital, by competences already present at the start of education, as suggested by the Screening theory literature, or by having attained the medical degree as such, as suggested by the literature on Credentialism? The study uses separate measurements of competence at the start and at the end of academic education. These are grade point averages (GPA's) of secondary school, available at the start of the first year of study, versus the final (medical) Skills test at the end of the study. Moreover, we use a direct measurement of competence development during medical education in the form of Progress Test results; the first Progress Test result in the first year, versus the final Progress Test result in the fourth year of study. This enables us to disentangle the effects of the three suggested mechanisms. The results suggest that after graduation the human capital factors available do not explain subsequent differences in labour market outcomes. The data therefore suggest evidence for Credentialism. However, selection processes during education and in the response to the labour market survey, take place on human capital acquired before and during education.
\end{abstract}

JEL-code: J24

Keywords: human capital, productivity 



\section{Introduction and Problem Statement}

\section{The selection and allocation process for physicians}

After medical students have passed their medical qualifying examination (after the doctoral program and two years of clinical clerkships), they face a rather unique selection and allocation process on the labour market. This process is different from the processes other academic graduates face, because of the typical features of the medical study: it is highly standardized for every student and it aims to prepare for further specialisation into highly professional medical jobs. These are to be obtained by following further educational trajectories that are combined with work in practice. Some empirical research on the transition from education to the labour market of physicians suggests that this further selection and allocation looks like a lottery (Borghans \& Ramaekers, 1993). No clear educational or human capital factors seem to explain the attainment of a specialisation position, or why one candidate is selected over another. ${ }^{1}$ Without any further explaining variables in, or during, medical education, it seems only possible to interpret the selection and allocation process for physicians directly after graduation, as a form of Credentialism (Collins, 1979). In this perspective, the amount of human capital, or indications/signals of future productivity do not play a role of importance.

In our view, randomness in selection, suggesting a solely certifying role of medical education seems illegitimate without a strong link with the underlying quality of what has been learnt. It is also at odds with educational literature concerning the relationship between medical competence and (better) professional functioning (see e.g., Norcini \& Lipner, 2000; Tamblyn et al., 1998). Specialisation positions differ in complexity and training intensity and graduates also differ in trainability, or learning competences, and acquired medical competences. Although following the same medical course offers the same minimum quality, there are still differences in the competences between good and mediocre students. Why then would these differences not predict the labour market chances of physicians, such as it would be expected to make a difference for other graduates from other study fields as well?

\section{Measurement Problems}

A possible reason of the apparent absence of relevant human capital predictors may be the lack of adequate measures. Trainability or learning competences and acquired medical competences are rarely measured as such, simply because measurements for these individual characteristics are scarce in labour market research (see e.g., Sørenson, 1994).

1. Others indicate that the attainment of a medical assistantship (not in training) in a hospital, after graduation, will increase the probability of obtaining a medical specialisation position (in training) afterwards (Van den Berg et al., 2002). This suggests a possible human capital or screening explanation, after already having entered the labour market. Because the amount of the working experience as a medical assistant seems to have no differentiating effect on the probability of becoming a specialist in training, the authors conclude the effect of having worked as a medical assistant is merely a signal for employers. It signals the expected productivity in, and/or interests of the candidates for a medical career as a specialist. This is in line with screening or sorting theory (see for example Thurow, 1975; Weiss, 1995). 
In educational research, such instruments are not easily available either. Many studies reveal that the assessment of competences during academic education is not always in line with the desired competence outcomes for students; examinations seem to direct the learning behaviour of students, leading sometimes to good study results (see e.g., Irandoust \& Karlsson, 2002), but not always to rooted (deeply incorporated) knowledge and competence (Verhoeven, 2003). It is therefore necessary to carefully consider the instruments used for measuring learning outcomes; whether they really refer to the presence of (development of) desired competence(s). Otherwise competence is measured that is not desirable and instruments will not be informative for explaining selection processes on the labour market. This may lead to possible wrong conclusions about the value of competences learnt in education.

\section{Purpose of the study}

In this study, we want to investigate the role of (medical) education by instruments used in the program, in the selection and allocation of physicians on the labour market. Educational empirical data concerning the learning competences and the more study specific competence development of the students are used. We use a rather unique data set of physicians graduated at Maastricht University (The Netherlands). These data contain several types of assessments during the medical study. These types of assessments have different measurement properties within the educational context. Thereby they measure different aspects of the (medical) competence students have to master at the end of their program. In addition, these different types of measurement have differential effects on the learning behaviour of the students. One type of assessment in particular, the so-called Progress Test, has revealed to have the desired effects on learning behaviour in an academic educational context (Verhoeven, 2003). The test measures growth in competence of students in the medical knowledge domain as defined by the educational end-objectives (Van der Vleuten et al., 1996). It is not possible to prepare oneself specifically for this test, since it measures the students' present knowledge of the complete medical domain. In other words, the test meets our criteria to measure the growth and final level in the actual acquired medical competences, at least for its knowledge component. It therefore refers to a form of human capital directly acquired in medical education. Two other types of assessment, the so-called Block Tests and Skills Tests, are more traditional instruments. Traditional in the sense that they measure the mastery of the content of certain courses covering well-defined subdomains of the medical knowledge domain, and the mastery of clinical procedures during diagnosis and medical practice in directly observed simulated situations, respectively. These tests have course tailored standards and do not measure growth in medical expertise components across time. For the Skills Test results at the end of the medical program (fourth year) this means the results may reflect directly acquired human capital in medical education, but this amount of acquired human capital cannot be compared to the amount in an earlier stage. The Block Test scores reflect the results of acquired human capital (knowledge component), but may also account for already present capacities of students in acquiring the knowledge, and therefore reflect a more 'screening', or 'signalling', element that may be of importance for employers. However, for Block Tests, studies have indicated that they are related to different, and perhaps less desirable learning style aspects than the Progress Tests (Van Berkel et al., 1995; Verhoeven, 2003). This is something to keep in mind when analysing the data and interpreting the results. We also include available grade point 
averages (GPA's) of secondary school as an indicator of the competence level before or at the start of the medical study. When relevant for labour market outcomes, these are indicating a more screening value of medical education, more than the Block Tests scores; by using GPA's we are able to measure the already present capabilities of people separately from competence development in medical education. Both will be related to labour market outcomes of physicians in terms of the type of medical job they have obtained, a year and a half after graduation. The value of the instruments used for labour market outcomes will be informative for the validity of the assumed mechanisms (Credentialism, Human Capital, Screening) in selection and allocation on the medical labour market.

The remainder of this paper will be organised as follows: in section 2, the theoretical background for our analyses will be presented. In section 3, the data and the method of research are addressed. In section 4 , the results of the analyses will be presented. Finally, in section 5 , conclusions and considerations for future research will be discussed.

\section{Theoretical background}

Three different explanations for the role of education in selection on the labour market. It goes without saying that having attained a medical degree as such plays an important role in the selection process. This degree is needed for legal functioning in the health sector as a physician. Without the medical certificate, no employer, no hospital, no health organization can hire a candidate as a physician. The question is however to what extent other and additional selection criteria play a role, or whether the medical degree serves as an sufficient entrance ticket to medical professions as suggested in the Credentials theory (Collins, 1979). The sufficiency of the medical degree is thus considered explanation one, referring to a Credential argument.

A second explanation points to the relation between success in education and learning capacities. When physicians enter the labour market, their learning process has far from ended. Specialisation programs, and other medical jobs as well, imply further learning to extend the already acquired basics of the academic medical program. It could therefore be of interest to future employers to select the candidate with the best learning or training ability. This is especially relevant for graduated physicians, because they face their rather unique labour market compared to other graduates, with many further training positions. The candidate with the best learning ability will have the best chance for succeeding in further specialisation and learning will occur at the smallest costs. In labour market research this line of thought is actually captured by the Screening or Signalling hypothesis (see for example Thurow, 1975; Spence, 1974). It states that employers use educational screening devices (like diploma's or study results) as signals about the underlying learning ability. In the case of our physicians, the medical degree is not differentiating as such, for screening purposes. However, (average) medical study achievements, or GPA's (of secondary school) may serve this purpose.

A third explanation pertains to the fact that individual differences in learning ability lead to individual differences in the acquisition and level of mastery of specific medical competences in education. These latter differences may play a role on their own in the selection and allocation on the labour market. Specialisation tracks and other medical jobs differ in length, intensity and in the type of (medical) competences required. Therefore, the more medical competences a graduate possesses, at the end of the academic medical study, the more attractive this graduate will be. This line of thought is supported by the Human Capital 
hypothesis (see for example Becker, 1983; McNabb, 1987). This hypothesis states that people acquire skills or competences during education that are relevant for their future jobs. These skills or competences make people more productive and thus attractive for the labour market. $^{2}$ Employers may therefore well be interested in indicators of direct productive competences of physicians. These competences, or aspects of competences, may well be reflected by the Progress test results at the end of medical education, especially when controlled for the start level (first Progress Test) and the Skills Test result at the end of education.

\section{Measurement problems with respect to selection criteria}

Finding relevant indicators for the role of education for selection and allocation has been rather problematic in labour market research, because the measurements are not well distinguished in sustaining the different explanations. One important reason for this is the absence of separate measures for learning capacities and acquired competences in education. Most indicators for schooling, like 'years of schooling', or 'attained level of education', or even the already mentioned 'study results' reflect both the ability to achieve a certain level (reflecting the amount of already present learning capacity), as well as the acquisition of certain skills. Although study achievement results may be appealing for the measurement of competence acquisition during education, the meaning of most traditional achievement results is not beyond an indication of the performance of a student on an educational test on a given moment in time, without a longitudinal perspective on what exactly has been learnt (see for example Lindblom-Ylänne \& Lonka, 2001; Baker, 2001). Therefore, study results can reflect both (already present) learning ability and a certain type of actual acquired competences, depending on the type of test (e.g., skills test, knowledge test).

In addition, the measurement of actual competence acquisition requires a direct monitoring of the actual learning process during education, thereby requiring certain features of the instrument, i.e. longitudinal measurement properties (standardized scale across measurements) and repeated measures. And this type of data is scarce (Sørensen, 1994).

A third problem is that learning ability (i.e. already present learning capacity) and the actual competence development during medical education may have interrelated or combined effects in assessment during the educational program. Separate effects on labour market outcomes may then be hard to determine, due to high correlations between the two. And multicollinearity may occur, that can lead to unjust inconsistent or insignificant results (see for example Ethington et al., 2002, for an explanation of the phenomenon; and Cawley et al., 2001, for an example of studying separate effects of 'cognitive ability' and 'education' on wages). It would require theoretically perfectly separated instruments for measuring both elements to overcome this problem. Instruments such as the Intelligence Quotient Score (IQ) or the Scholastic Aptitude score are used for measuring learning ability in terms of cognitive aptitudes (see e.g., Atkinson et al., 1987). However, others argue that 'learning ability'

2. Apart from the purely selective criteria from the view of the employer, individual preferences with respect to work and the individuals' self-knowledge of medical and other work related competences will lead to a certain amount of self-selection of candidates for specialisation tracks or other medical jobs. 
should, or cannot be separated from the specific competence for which it is used (see e.g., Perkins \& Salomon, 1989; Glaser, 1990). This implies that the development of competence during education also captures already present (learning) abilities.

\section{Some solutions to the measurement problems}

One solution put forward in this paper to overcome the before-mentioned problems is the use of a specific test, the so-called Progress Test. This test is considered to measure the growth in cognitive competence (knowledge) concerning the entire medical domain (Van der Vleuten et al., 1996). In section 3 (data and methodology) this test will be discussed in detail. However, the availability of this instrument will not guarantee a separate measurement of a specific component in the competence development process. It may also capture more generic capacities of competence of people, such as their learning ability to acquire this specific knowledge.

Therefore, the second solution we put forward in this paper is to separate measurements relevant for the different assumed selection and allocation mechanisms on the labour market in time: we will measure the competence level of students at the start of their medical education (referring to the more screening mechanism) and the competence development and competence level at the end of their education (referring to the more human capital acquisition mechanism). In this way, the competences already present before education and the competences actually developed in education can be separated. Then, under the restriction that we are able to avoid multicollinearity, we will be able to test the labour market theoretical inferences about the role of education for physicians. The research question then is whether medical education really adds labour market important competences during the educational process (human capital), or whether the competences already present before or at the start of medical education can already explain selection and the labour market outcomes (signalling and/or screening), or whether the attainment of the medical degree as such will explain it all, without further consideration of skills (referring to credentialism).

\section{Research model and hypotheses}

For the selection and allocation process on the labour market for physicians, we argued three elements can be measured separately; the medical degree as such, the competences learnt during medical education (by indicators of competence at the end of the academic program, i.e. the final Progress Test, the Skills Test and the mean Block Test scores of the fourth year), and the level of competence already present at the start or even before the start of medical education (by indicators of competence at the start of the academic program, i.e. GPA's, the first Progress Test in the first year, and the mean Block Test scores of the first year). The relations of the competence levels with labour market outcomes are presented in figure 1. 


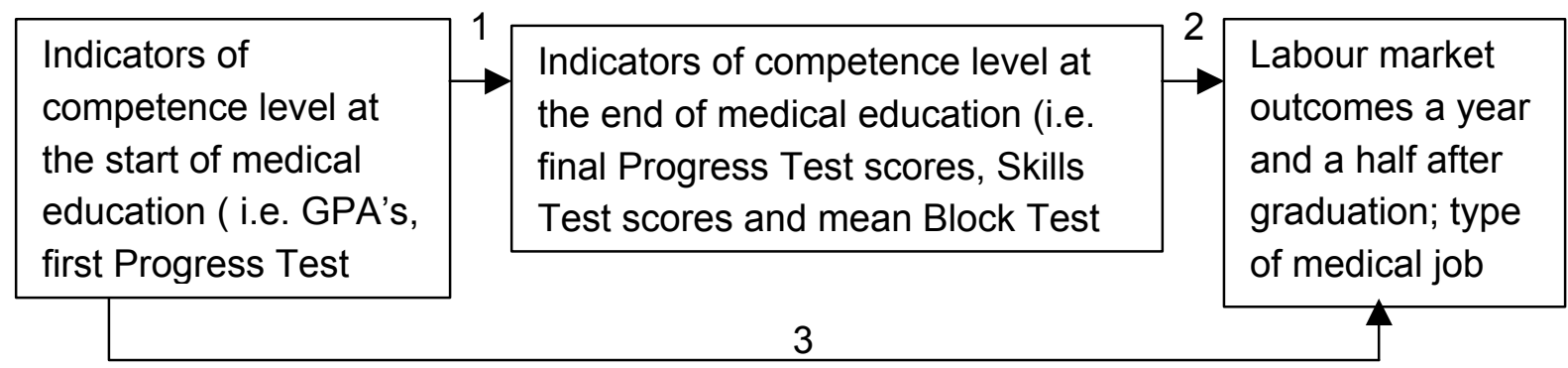

Figure 1

Model of possible effects of competence levels at different times in the educational process on labour market outcomes for physicians

When the role of education is merely to guarantee an entrance ticket, we expect no further effects of competence levels at the start or at the end of education on labour market outcomes. This means we expect no effects of relations 2 and 3 . In this case, findings could be interpreted in terms of evidence for the Credentialism mechanism. The existence of a possible positive relation 1 is not exclusive for one theoretical assumption. However, Crendentialism leaves it out of consideration entirely, whereas Screening and Human Capital can very well explain such a relation. When medical education is merely important for its reflection of a desired competence level already present before the actual medical training takes place (as can be explained by the Screening thought), indicators of competence levels at the start of the medical program must have an effect on labour market outcomes (3). It is likely, though, that the competence level at the start of medical education will affect the competence development and subsequently the acquired level of competence at the end of medical education $(1,2)$. Therefore, when the medical program itself adds competences relevant for work (such as can be explained by Human Capital theory), the acquired competence level at the end of education must be of relevance (2), even after controlling for the effects of previous competence levels. It may also be possible that both the competence level at the start as well as the competence level at the end of medical education will have independent effects on labour market outcomes, resulting in positive relations 2 and 3, after controlling for relation 1.

More specifically, the following relations will be tested:

a Indicators of competence at the end of the medical study (acquired competence) affect individual labour market outcomes (human capital, relation 2, controlled for 1);

b Indicators of competence at the start of the study affect labour market outcomes, even after controlling for the effects of end-level indicators (screening argument, relation 3, and 1 controlled for 2 ).

The relation between the start level indicators of competence and the end level indicators of competence (relation1 in the research model) will be tested independently and explicitly as well, although this is not the main theoretical focus of this paper. Therefore the results of this analysis will be dealt with in an appendix (i.e. Appendix 4).

In the following section, the data and methodology for testing the research model will be outlined. 


\section{Data and methodology}

\section{Subjects}

The research population consists of medical students of Maastricht University, who started their medical study in 1989-1991.

\section{Instruments for competence measurement}

Indicators of the competence level at the start of the medical program are:

- GPA's (Mean final exam scores secondary school);

- First Progress Test score in the first year of study;

- Mean Block Test scores of the first year.

Indicators of the competence level at the end of the medical program are:

- Final Progress Test score of fourth year;

- Mean Block Test scores of fourth year;

- Skills Test score of fourth year.

Multiple indicators are used, because of their differentiated measurement properties and their possibly different importance in measuring what employers may be interested in (such as specific medical skills, specific medical knowledge, or a more generic indication of the already present learning capacity of graduates).

The data used for competence indicators have the following features:

Progress Test scores: these are gathered during the medical program four times a year and capture the growth in specific medical competence (knowledge aspect) during the years of study, because each tests covers the total relevant medical knowledge domain. The total score on the test is expressed as a percentage of the correct answers minus the incorrect answers. The Progress Test scores meet to a large extent the measurement criteria as proposed by Sørensen (1994) to be able to measure actual competence development during education. Although the medical study takes 6 years, we will use the first Progress test score of the first year of study as an indication of competence at the start of medical education, and the final Progress test score of the fourth year (final year of doctoral program) as an indication of the competence level at the end of the medical program (referring to actual acquired human capital in education). The last two years of the medical study are meant for the so-called clerkships, in which working and learning in practice is the most important element. For detailed information about the Progress Test, its validity and reliability for our measurement purpose, and relevant references, we refer to Appendix 1.

Block Test scores: these are gathered six times a year and cover only course-related subdomains of medical expertise. It is basically a knowledge test of about 150 items that is administered after every block period (curriculum unit) of six weeks. It covers the contents of the course and tests the mastery of end-objectives of the course on a percentage scale. Therefore these tests give no information on the general growth in medical competence. They reflect whether the student has passed the course successfully. We will use the mean Block Test scores of the first year and the mean scores of the fourth year (final year of the 
doctoral program) as indicators of competence at the start and at the end of medical education respectively.

Skills Test scores: these are gathered only once a year during the medical program. They are aimed at testing mastery of clinical procedural skills through direct observation of students carrying out these skills across a number of simulated clinical situations. Trained examiners use checklists to score performance. Percentage scores reflect the amount of well-performed tasks as registered. The test covers an increasing amount of clinical skills every year, in line with the skills students are trained for.

We use the Skills tests scores of the fourth year of the medical program as an indicator of the end-level competence of students (acquired human capital). The reason we make no use of the first year scores for an indication of start level competence is that the test is administered at the end of the first study year and therefore probably biased by learning effects of a complete year of study.

GPA's: the grade point averages (mean final exam scores of secondary school) are a highly standardized measure in the Netherlands expressed on a scale from 1-10. They determine whether the student has successfully passed the secondary school (scores 5.5-10) or not (scores 1-5.4) and therefore reflect the attained school-success of the graduates before entering the medical program. In our sample, only scores between 5.5 and 10 are possibly present, since not having passed the final exam will not allow one to enter medical education.

When you have passed the final exam, students for medicine are selected on their GPA's. However, in the Netherlands, this did not mean you had no chance to enter the program when you were not scoring very high in our research sample (students starting in1998-1991): students were grouped based on ranges of GPA-scores. Only a certain percentage of each group was allowed to enter, and the selection of students for this percentage was at random. When you were part of the group with the highest scores, you were part of a relative small group. Your individual chance to enter the program was then higher than for lower scoring students. They were part of a larger group what therefore decreased their individual chance to be selected. We use GPA's as an indicator of the competence level at the start of medical education, referring to a possible signal or screening device for employers.

\section{Instrument for the measurement of labour market outcomes}

Labour market information is gathered by a labour market survey enclosing our subjects who started their medical study in 1989-1991. This labour market survey is conducted every year by the Research Centre of Education and the Labour Market (Dutch short-cut ROA) and gathers labour market information, as well as educational evaluative data, from graduates one year and a half after graduation. The graduation cohorts of 1995-2000 are included to obtain our research sample of about 290 physicians for whom data for all our educational variables (competence levels at the start and at the end of medical education) and our labour market outcome variables in terms of obtained position are available.

Specifically, the following labour market indicators are used from the labour market survey, pertaining to job chances and the quality of the job (Van der Velden \& Wieling, 1994):

- Having a physicians' job (dummy variable); 
- Having a specialisation position (dummy variable);

- Category of common types of jobs/positions; in training for social medicine jobs ${ }^{3}(1)$,

- for general practitioner (2), or for a hospital specialisation (3), resident not in training

- (4) and PhD students (5);

- Type of specialisation ordered by required training period, reflecting further investment in human capital and thereby expected lifetime income; in training for social medicine jobs (1), for general practitioner (2), or for a hospital specialisation (3).

For further argumentation on the use of these labour market indicators, see Appendix 2.

\section{Control Variables}

In addition, personal data are included in the analyses as relevant control variables. These are gender and age. After graduation mostly women are interested in part-time work. Possibilities for part-time work are largest in social medicine positions, even during the training period. Age may play a role because it reflects experience gained in earlier work and life (human capital argument). On the other hand, age may also have a negative effect, because the returns on investments become relative low for a candidate (human capital argument), and/or a candidate may become less flexible with age, which can interfere with the demanding learning process in specialisation (selection argument).

Socialisation processes are important learning sources for physicians (Slotnick, 2001). The (self-) selection on age fits this context. In all, the age effect will depend on the range in ages among the research subjects. As a final control variable, year of entry in the labour market will be used, to control for fluctuations in the labour market demand of physicians for specific (specialisation) jobs.

\section{Method of analysis}

We will test the effects of education on the different labour market outcomes in different (sub) models; in the first model, we will estimate the effects of the competence level at the start of

the medical education (in fact the Screening mechanism). In the second model, the effect of the competences at the end of medical education will be tested (in fact the mechanism of acquired Human Capital). In the third and final model, both indicators of competence level at the start as well as indicators of competence level at the end of medical education are included, to measure their combined effects. In all three models we control for age, gender and year of entry in the labour market. For the different labour market indicators, binary logistic regression, multi-nominal logistic regression and ordinal regression analyses are used.

Before conducting the labour market analyses, the data will be controlled for multicollinearity and selection bias in the research subjects' competence scores. The relation between the start level indicators of competence and the end level indicators will be dealt with in Appendix 4 by normal regression analysis.

3. Social Medicine in the Netherlands includes occupational (and insurance) medicine on the one hand, and public health (including a.o. mother-and-child care, sports medicine and epidemiology) on the other hand. 


\section{Results}

\section{Descriptives for all variables}

Descriptive results of all variables used in the analyses and Pearson's correlations are presented in table 1. All study results variables in table 1 reflect percentile scores of correct or correct-minus-incorrect answers. However, the GPA's are on a scale from 1-10 and because all students have passed the exam, only scores from 6-10 are present in our sample. Correlations between study variables are significantly positive. The largest correlation is between the final Progress Test and the mean Block Test score of the fourth year for the end-level indicators, even larger than the considerable correlations between the first and fourth year Block Test scores, and between the GPA's and the mean first year Block Test scores. This suggests the measurement of common elements at both the start and end of education by different knowledge testing instruments. Because the correlations are considerably high (ranging from 0.517 to 0.574 ), we consider the presence of multicollinearity between the different instruments at the start and at the end of education before conducting further analyses. We do this by comparing the effects of the different instruments together and separately on labour market outcomes, as well as in different combinations (pairs of predictors). It appears that the effects of the Mean Block Test scores, both at the start and at the end of education, seem to cause the largest differences in parameter estimates ( $B$ 's and s.e.'s), when including more predictors in the models. These differences appear to be larger than may be expected, based on the separate effects of the different instruments. Without including the Mean Block Test scores, the possible problem of multicollinearity seems omitted. Therefore we decide to leave the Mean Block Test scores out of further analysis.

Another possible problem for the interpretation of our results refers to selective processes affecting the competence levels. Selective processes may bias the effects of competence indicators on the acquisition of competence in academic education, graduation, and responding to the labour market survey. Although internal publications indicate that drop-out (selection bias) among students in medicine is often due to other (more personal) factors than differences in competence levels (Van Luijk et al., 1990; Perquin, 1999), we like to empirically consider the possible selectivity in our analyses. We do this by conducting sequential logistic regression analyses with our competence indicators for three relevant selective moments, i.e. the availability of our end-level competence indicators for the students who started the medical study, graduation by the year 2000 , and response to the labour market survey. The results of these sequential analyses and the differences in the means of the competence level indicators are presented in table I in appendix 3 . They reveal that for all our competence instruments used, the subjects in our remaining research sample have already higher scores due to selective processes during education, graduation by the year 2000 , and/or responding to the labour market survey. We should take this into account when interpreting the results of our further analyses, i.e., the effects of the scores on our instruments on labour market outcomes for physicians. 
Table 1

Descriptive statistics and Pearson's correlations

\begin{tabular}{|c|c|c|c|c|c|c|c|c|c|c|c|c|c|c|c|c|}
\hline & & & & & Correlatio & Coëfficien & & & & & & & & & & \\
\hline Variables & Mean & SD & $\mathrm{N}$ & 1 & 2 & 3 & 4 & 5 & 6 & 7 & 8 & 9 & 10 & 11 & 12 & 13 \\
\hline Indicators of Labour Market Entry Su & & & & & & & & & & & & & & & & \\
\hline 1) Being employed as a physician & 0,984 & 0,127 & 489 & & & & & & & & & & & & & \\
\hline in analyses: & 0,983 & 0,129 & 295 & & & & & & & & & & & & & \\
\hline 2) Having obtained a specialization position & 0,430 & 0.490 & 484 & & & & & & & & & & & & & \\
\hline in analyses: & 0,430 & 0.500 & 291 & & & & & & & & & & & & & \\
\hline Specialisation/Job category: & & & & & & & & & & & & & & & & \\
\hline 3) Social medicine & 0,069 & 0,253 & 480 & & & & & & & & & & & & & \\
\hline in analyses: & 0,073 & 0,261 & 288 & - & - & - & & & & & & & & & & \\
\hline 4) General practitioner & 0,166 & 0,372 & 483 & & & & & & & & & & & & & \\
\hline in analyses: & 0,182 & 0,387 & 291 & - & - & - & - & & & & & & & & & \\
\hline 5) Hospital specialisation & 0,138 & 0,346 & 484 & & & & & & & & & & & & & \\
\hline in analyses: & 0,130 & 0,337 & 292 & - & - & - & - & - & & & & & & & & \\
\hline 6) Resident not in training & 0,468 & 0,500 & 483 & & & & & & & & & & & & & \\
\hline in analyses: & 0,462 & 0,499 & 292 & - & - & - & - & - & - & & & & & & & \\
\hline 7) PhD student & 0,048 & 0,213 & 483 & & & & & & & & & & & & & \\
\hline in analyses: & 0,048 & 0,214 & 292 & - & - & - & - & - & - & - & & & & & & \\
\hline Competence level start medical educ & & & & & & & & & & & & & & & & \\
\hline 8) GPA's & 6,858 & 0,652 & 1434 & & & & & & & & & & & & & \\
\hline in analyses: & 6,883 & 0,673 & 295 & 0,055 & 0,010 & $-0,095$ & 0,054 & 0,041 & 0,007 & $0,103^{*}$ & - & & & & & \\
\hline 9) First Progress Test score in first year & 9,884 & 12,010 & 968 & & & & & & & & & & & & & \\
\hline in analyses: & 4,619 & 3,276 & 295 & 0,025 & 0,080 & 0,034 & $0,141^{* *}$ & $-0,059$ & $-0,121^{* *}$ & 0,029 & 0,082 & - & & & & \\
\hline 10) Mean Block Test score first year & 45,174 & 7,723 & 746 & & & & & & & & & & & & & \\
\hline in analyses: & 45,922 & 7,141 & 295 & 0,012 & $-0,010$ & $-0,123^{\star *}$ & 0,095 & $-0,060$ & $-0,003$ & $0,129^{* *}$ & $0,517^{\star * *}$ & $0,170^{\star \star \star}$ & * - & & & \\
\hline Competence level and medical educ & & & & & & & & & & & & & & & & \\
\hline 11) Final Progress Test score in fourth year & 32,256 & 8,164 & 727 & & & & & & & & & & & & & \\
\hline in analyses: & 33,674 & 7,858 & 295 & 0,033 & 0,051 & $-0,071$ & 0,011 & 0,070 & $-0,068$ & 0,053 & $0,352^{\star * *}$ & 0,020 & $0,362^{* * *}$ & - & & \\
\hline 12) Mean Block Test score of fourth year & 41,287 & 6,740 & 723 & & & & & & & & & & & & & \\
\hline in analyses: & 42,671 & 6,584 & 295 & 0,043 & 0,080 & $-0,030$ & 0,093 & $-0,001$ & $-0,062$ & $0,108^{*}$ & $0,344^{* * *}$ & $-0,003$ & $0,552^{* * *}$ & $0,574^{* \star *}$ & - & \\
\hline 13) Skills Test score of the fourth year & 80,107 & 8,321 & 683 & & & & & & & & & & & & & \\
\hline in analyses: & 81,680 & 7,346 & 295 & 0,031 & 0,081 & $-0,062$ & 0,078 & $-0,004$ & $-0,029$ & 0,023 & $0,235^{* \star *}$ & 0,005 & $0,359^{* \star *}$ & $0,240^{* * *}$ & $0,382^{* * *}$ & \\
\hline
\end{tabular}


Table 1 (continued)

Descriptive statistics and Pearson's correlations

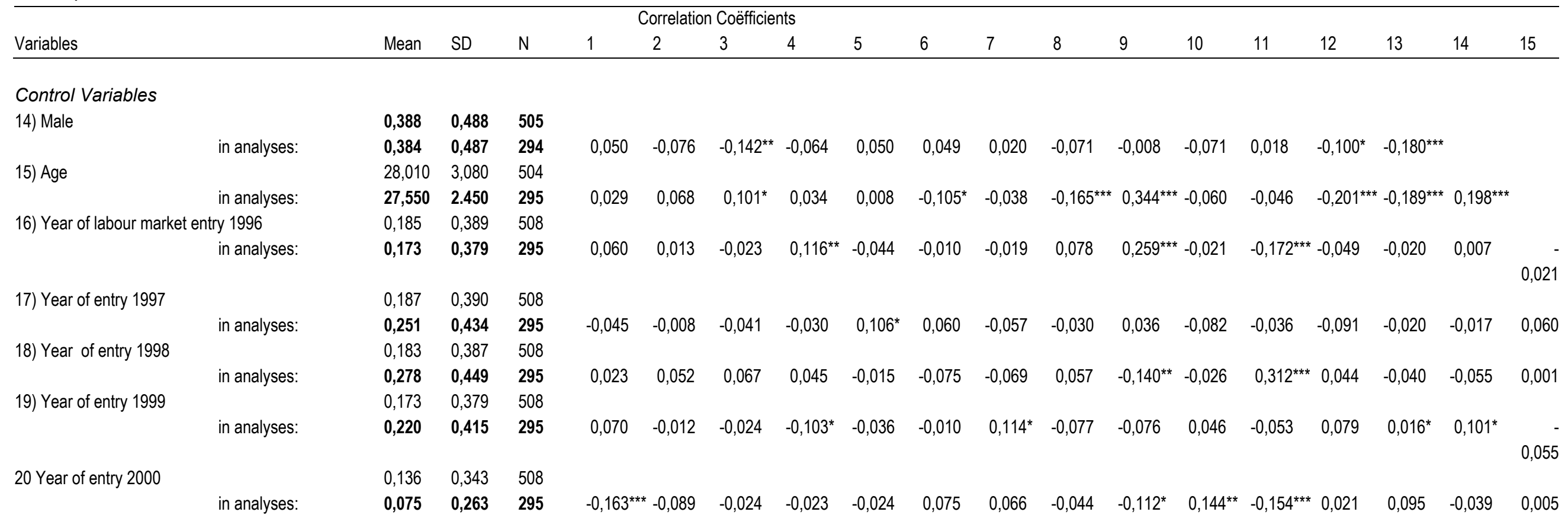

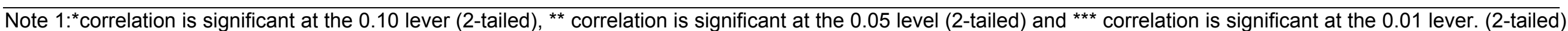

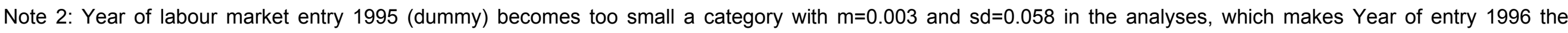
reference category. 


\section{Effects of levels of competence on obtaining a physicians' job}

Based on table 1, we can argue that almost all graduates have obtained a physicians' job a year and a half after graduation (almost $98,5 \%$ ). This is considered and confirmed for all available (non-matching) cases in the labour market survey data as well. It is therefore almost superfluous to conduct a logistic regression for this indicator, because almost no variation is present. The binary logistic regression analyses indeed confirm this expectation, by revealing no effects of any of the (competence) variables included in the analyses. The results are presented in table 2 . As can be seen from table 2, only positive effects of year of entry (1998) in the labour market appear. So far, the medical study seems to garantee a medical job after graduation.

Table 2

Regression estimates of the effects of competence levels at the start and at the end of medical education on having a physicians' job a year and a half after graduation

\begin{tabular}{|c|c|c|c|c|c|c|}
\hline & \multicolumn{2}{|c|}{ Model 1} & \multicolumn{2}{|c|}{ Model 2} & \multicolumn{2}{|c|}{ Model 3} \\
\hline & B & s.e. & $\mathrm{B}$ & s.e & $\mathrm{B}$ & s.e. \\
\hline Constant & $-9,393$ & 11,733 & $-6,183$ & 9,770 & $-12,821$ & 12,667 \\
\hline \multicolumn{7}{|l|}{$\begin{array}{l}\text { Competence level start medical } \\
\text { education }\end{array}$} \\
\hline GPA's & 0,716 & 0,635 & & & 0,739 & 0,667 \\
\hline First Progress Test score first year & $-0,359$ & 0,704 & & & $-0,456$ & 0,739 \\
\hline \multicolumn{7}{|l|}{$\begin{array}{l}\text { Competence level and medical } \\
\text { education }\end{array}$} \\
\hline Final Progress Test 4th year & & & 0,050 & 0,582 & $-0,235$ & 0,661 \\
\hline Skills Test score 4th year & & & 0,608 & 0,520 & 0,725 & 0,603 \\
\hline \multicolumn{7}{|l|}{ Control Variables } \\
\hline Male & 0,489 & 1,154 & 0,857 & 1,235 & 0,829 & 1,239 \\
\hline Age & 0,424 & 0,435 & 0,301 & 0,363 & 0,539 & 0,469 \\
\hline Year of entry 1996 & 9,668 & 60,717 & 9,982 & 60,405 & 9,888 & 59,549 \\
\hline Year of entry 1997 & 1,308 & 1,073 & 1,407 & 1,123 & 1,649 & 1,187 \\
\hline Year of entry 1998 & $2,290^{*}$ & 1,294 & $2,281^{*}$ & 1,310 & $2,688^{*}$ & 1,400 \\
\hline Year of entry 1999 & 10,214 & 52,650 & 10,011 & 53,322 & 10,746 & 49,365 \\
\hline \multicolumn{7}{|l|}{ Model Statistics } \\
\hline Number of cases $(n)$ & & 294 & & 294 & & 294 \\
\hline Model chi-square & & 10,473 & & 10,328 & & 11,876 \\
\hline d.f. & & 8 & & 8 & & 10 \\
\hline$p$ & & 0,233 & & 0,243 & & 0,293 \\
\hline
\end{tabular}

Note 1: standardized values are used for all competence indicator variables

Note 2: Year of entry 2000 is the reference category for the 'year of entry' control variables 


\section{Effects of competence levels on obtaining a specialisation position}

For our second labour market indicator, obtaining a specialisation position (dummy), it appears from table 1 that $43 \%$ of those who work as a physician indeed has obtained one. With a binary logistic regression we measure the effects of competence indicators at the start and at the end of medical education on having acquired a specialisation position. The results of the analyses are presented in table 3.

Table 3

Regression estimates of the effects of competence levels at the start and at the end of medical education on having a specialisation position a year and a half after graduation

\begin{tabular}{|c|c|c|c|c|c|c|}
\hline & \multicolumn{2}{|c|}{ Model 1} & \multicolumn{2}{|c|}{ Model 2} & \multicolumn{2}{|c|}{ Model 3} \\
\hline & B & s.e. & B & s.e & B & s.e. \\
\hline & & & - & & & \\
\hline Constant & $-2,645$ & 1,638 & $3,266^{* *}$ & 1,567 & $-3,070^{*}$ & 1,689 \\
\hline \multicolumn{7}{|l|}{ Competence level } \\
\hline start medical education & 0,016 & 0,122 & & & $-0,034$ & 0,133 \\
\hline GPA's & 0,074 & 0,212 & & & 0,053 & 0,213 \\
\hline \multicolumn{7}{|c|}{ First Progress Test score first year } \\
\hline \multicolumn{7}{|l|}{$\begin{array}{l}\text { Competence level } \\
\text { end medical education }\end{array}$} \\
\hline Final Progress Test 4th year & & & 0,025 & 0,131 & 0,034 & 0,138 \\
\hline Skills Test score 4th year & & & 0,191 & 0,136 & 0,193 & 0,137 \\
\hline \multicolumn{7}{|l|}{ Control Variables } \\
\hline Male & $-0,401$ & 0,256 & $-0,361$ & 0,259 & $-0,359$ & 0,260 \\
\hline Age & 0,071 & 0,056 & $0,090^{*}$ & 0,054 & 0,084 & 0,058 \\
\hline Year of entry 1996 & 0,671 & 0,542 & 0,668 & 0,542 & 0,681 & 0,545 \\
\hline Year of entry 1997 & 0,536 & 0,515 & 0,573 & 0,516 & 0,558 & 0,519 \\
\hline Year of entry 1998 & 0,725 & 0,511 & 0,794 & 0,512 & 0,777 & 0,515 \\
\hline Year of entry 1999 & 0,575 & 0,526 & 0,614 & 0,526 & 0,595 & 0,528 \\
\hline \multicolumn{7}{|l|}{ Model Statistics } \\
\hline Number of cases $(n)$ & & 290 & & 290 & & 290 \\
\hline Model chi-square & & 6,237 & & 8,476 & & 8,589 \\
\hline d.f. & & 8 & & 8 & & 10 \\
\hline $\mathrm{p}$ & & 0,621 & & 0,388 & & 0,571 \\
\hline
\end{tabular}

Note 1: standardized values are used for all competence indicator variables

Note 2: Year of entry 2000 is the reference category for the 'year of entry' control variables

* significant at the 0.1 level

The results show no effects for any of the included competence indicators. The findings suggest there are no explaining effects of competence levels on the chances for obtaining a 
specialisation as such. Only a slightly significant positive effect of age is found in the second model. Therefore we may conclude that the results so far suggest evidence for the Credential argument; the medical degree as such is sufficient for a relevant job and obtaining a specialisation position is merely a matter of luck (or other selection criteria not included in our analyses) afterwards.

However, the selection bias in our data indicates there is more to conclude. And in addition, both in specialisation positions and in non-specialisation positions heterogeneity can be assumed to be present (see appendix 2 for argumentation). Therefore we continue with considering the effects of the more qualifying and screening role of education on the chances to obtain different types of jobs (specialisation positions and non-specialisation positions).

\section{Effects of competence levels on obtaining different types of physicians' jobs}

We conduct multi-nominal regression analyses (MNRA) for the largest categories of jobs in the sample, consisting of residents not in training, medical Ph.D. students, residents in training for hospital specialisations, general practitioners in training (GP's in training), and physicians in training for specialisations in social medicine. Table 4 presents the results.

As table 4 indicates, we took the hospital specialisation positions as the reference category. The following effects are found:

The negative effect of being male for the social medicine category compared to the hospital specialists in training is in all three models consistent; being female enlarges your chance to obtain a training position in social medicine after graduation considerably. To a much smaller extent, a higher age enhances your chance to obtain the same type of job as well.

In the second model, the end-level competence indicators are tested; negative effects are found for the final Progress Test score for physicians in a training position for social medicine (compared to the hospital specialists in training). A one standard deviation higher score on the final Progress Test leads to significant negative effects on the odds of obtaining a training position in social medicine, compared to becoming a hospital specialist in training of 0.56 , implying a decrease of $44 \%$ in the odds ratio. This is the expected change, remaining all other variables constant. In terms of what this decrease will mean for one's chance to obtain a training position in social medicine, the odds ratio can be written as the relative chance to obtain this type of job $(\mathrm{sm})$, compared to a hospital specialisation in training job (hs) and calculate the differences in the chance for different values of the separate (relevant) variables, by considering a reference person (for example a female with mean age, with mean scores on the competence indicators, entered in the labour market in the reference year 2000).

These differences in the chance to obtain a training position in social medicine are presented in table 5 based on our reference person. We include the relevant effects of gender, age, and the final Progress Test score from the second model of our MNRA, to show their separate effects on the chance, remaining the other variables constant. 
Table 4

Estimates of the effects of competence level indicators on having different types of jobs (not in specialisation and specialisation positions) compared to having a hospital specialisation position (resident in training)

\begin{tabular}{|c|c|c|c|c|c|c|c|c|c|c|}
\hline & \multicolumn{2}{|c|}{ General Practitioner } & \multicolumn{2}{|c|}{ Social Medicine } & \multicolumn{2}{|c|}{ Resident not in training } & \multicolumn{2}{|c|}{ PhD student } & \multicolumn{2}{|c|}{ Model statistics } \\
\hline & estimate & s.e. & estimate & s.e. & estimate & s.e. & estimate & s.e. & $\mathrm{n}$ & $\begin{array}{c}-2 \text { Log } \\
\text { Likelihood }\end{array}$ \\
\hline \multicolumn{11}{|l|}{ model 1} \\
\hline Intercept & 1,073 & 2,830 & $-5,163$ & 3,349 & 4,064 & 2,669 & 1,930 & 4,457 & 260 & 634,507 \\
\hline \multicolumn{11}{|l|}{ Competence level start medical education } \\
\hline GPA's & $-0,079$ & 0,219 & $-0,514$ & 0,331 & $-0,119$ & 0,187 & 0,399 & 0,313 & & \\
\hline First Progress Test first year & 0,565 & 0,371 & $-0,270$ & 0,484 & 0,075 & 0,324 & 0,521 & 0,560 & & \\
\hline \multicolumn{11}{|l|}{ Control Variables } \\
\hline Male & $-0,504$ & 0,466 & $-2,133^{\star * *}$ & 0,830 & $-0,097$ & 0,387 & 0,107 & 0,678 & & \\
\hline Age & $-0,012$ & 0,094 & $0,190^{*}$ & 0,109 & $-0,078$ & 0,090 & $-0,069$ & 0,156 & & \\
\hline Year of entry 1996 & 0,888 & 1,070 & $-0,222$ & 1,271 & $-0,282$ & 0,917 & $-0,825$ & 1,348 & & \\
\hline Year of entry 1997 & $-0,649$ & 1,011 & $-1,048$ & 1,202 & $-0,859$ & 0,835 & $-2,100^{*}$ & 1,276 & & \\
\hline Year of entry 1998 & 0,047 & 1,012 & 0,058 & 1,169 & $-0,645$ & 0,856 & $-1,788$ & 1,285 & & \\
\hline Year of entry 1999 & $-0,387$ & 1,078 & $-0,209$ & 1,244 & $-0,460$ & 0,890 & $-0,194$ & 1,179 & & \\
\hline \multicolumn{11}{|l|}{ model 2} \\
\hline Intercept & $-1,349$ & 2,563 & $-4,667$ & 2,933 & 3,800 & 2,500 & 1,884 & 4,419 & 260 & 640,945 \\
\hline \multicolumn{11}{|l|}{ Competence level end medical education } \\
\hline Final Progress Test score fourth year & $-0,232$ & 0,230 & $-0,587^{*}$ & 0,325 & $-0,246$ & 0,198 & 0,153 & 0,337 & & \\
\hline Skills Test score fourth year & 0,276 & 0,240 & $-0,104$ & 0,287 & 0,020 & 0,197 & 0,023 & 0,368 & & \\
\hline \multicolumn{11}{|l|}{ Control Variables } \\
\hline Male & $-0,501$ & 0,469 & $-2,136^{* *}$ & 0,835 & $-0,091$ & 0,392 & $-0,137$ & 0,675 & & \\
\hline Age & 0,065 & 0,086 & $0,178^{*}$ & 0,098 & $-0,071$ & 0,085 & $-0,066$ & 0,154 & & \\
\hline Year of entry 1996 & 0,807 & 1,063 & $-0,177$ & 1,272 & $-0,213$ & 0,919 & $-1,013$ & 1,319 & & \\
\hline Year of entry 1997 & $-0,426$ & 1,001 & $-1,090$ & 1,181 & $-0,780$ & 0,833 & $-2,006$ & 1,264 & & \\
\hline
\end{tabular}


Table 4 (continued)

Estimates of the effects of competence level indicators on having different types of jobs (not in specialisation and specialisation positions) compared to having a hospital specialisation position (resident in training)

\begin{tabular}{|c|c|c|c|c|c|c|c|c|c|c|}
\hline & \multicolumn{2}{|c|}{ General Practitioner } & \multicolumn{2}{|c|}{ Social Medicine } & \multicolumn{2}{|c|}{ Resident not in training } & \multicolumn{2}{|c|}{ PhD student } & \multicolumn{2}{|c|}{ Model statistics } \\
\hline & estimate & s.e. & estimate & s.e. & estimate & s.e. & estimate & s.e. & $r$ & $\begin{array}{c}-2 \text { Log } \\
\text { Likelihood }\end{array}$ \\
\hline Year of entry 1998 & 0,259 & 1,004 & $-0,041$ & 1,137 & $-0,596$ & 0,852 & $-1,675$ & 1,278 & & \\
\hline Year of entry 1999 & $-0,192$ & 1,070 & $-0,260$ & 1,216 & $-0,400$ & 0,885 & $-0,196$ & 1,170 & & \\
\hline \multicolumn{11}{|l|}{ model 3} \\
\hline Intercept & 0,638 & 2,860 & $-5,319$ & 3,462 & 4,064 & 2,683 & 1,955 & 4,418 & 260 & 632,671 \\
\hline \multicolumn{11}{|l|}{ Competence level start medical education } \\
\hline GPA's & $-0,051$ & 0,234 & $-0,330$ & 0,356 & $-0,053$ & 0,198 & 0,402 & 0,341 & & \\
\hline First Progress Test score first year & 0,539 & 0,372 & $-0,268$ & 0,490 & 0,068 & 0,322 & 0,485 & 0,559 & & \\
\hline \multicolumn{11}{|l|}{ Competence level end medical education } \\
\hline Final Progress Test score fourth year & $-0,232$ & 0,242 & $-0,489$ & 0,343 & $-0,228$ & 0,206 & $-0,036$ & 0,360 & & \\
\hline Skills Test score fourth year & 0,258 & 0,245 & $-0,024$ & 0,295 & 0,021 & 0,198 & $-0,044$ & 0,369 & & \\
\hline \multicolumn{11}{|l|}{ Control Variables } \\
\hline Male & $-0,442$ & 0,474 & $-2,109^{* *}$ & 0,835 & $-0,084$ & 0,395 & 0,070 & 0,694 & & \\
\hline Age & $-0,001$ & 0,095 & $0,192^{*}$ & 0,111 & $-0,080$ & 0,090 & $-0,069$ & 0,153 & & \\
\hline Year of entry 1996 & 0,990 & 1,078 & $-0,098$ & 1,280 & $-0,204$ & 0,922 & $-0,827$ & 1,353 & & \\
\hline Year of entry 1997 & $-0,563$ & 1,016 & $-0,948$ & 1,211 & $-0,800$ & 0,839 & $-2,068$ & 1,277 & & \\
\hline Year of entry 1998 & 0,136 & 1,018 & 0,127 & 1,181 & $-0,617$ & 0,861 & $-1,780$ & 1,291 & & \\
\hline Year of entry 1999 & $-0,298$ & 1,082 & $-0,174$ & 1,250 & $-0,433$ & 0,894 & $-0,201$ & 1,183 & & \\
\hline
\end{tabular}

Note 1: Standardized values have been used for all competence variables

Note 2: Year of entry 2000 is the reference category (dummy control variables)

${ }^{*}$ significant at $0.10,{ }^{* *}$ significant at 0.05 and ${ }^{* * *}$ significant at 0.01 
Table 5

Changes in chance to obtain a training position in social medicine (sm) compared to a hospital specialisation in training position (hs)

Chance to obtain sm versus hs

Chance for reference person:

model 2 of the MNRA

$14 \%$

Changes in chance for relevant predictors:

Age:

27,55

30

Gender:

female

male

fPTscore fourth year:

0

(mean)

$(+1 s d)$

$+10.3 \%$

(reference)

(standardized mean)

$(+1 \mathrm{sd})$

$-12 \%$

1

$-4.5 \%$

Note 1: the reference person has mean age, is female, has mean competence indicator scores and entered the labour market in 2000 (reference category)

Note 2: $\mathrm{fPT}$ score $=$ final Progress Test score

Returning to table 5, in the third model of our MNRA, including both start-level and end-level competence indicators, no effects of any of the competence indicators have left. Only the already mentioned effects of gender and age remain present. Apparently, in the end, the selection of candidates for different physicians' jobs seems not to be regulated by their competence levels very much, at least not in our research sample.

Although the results of our MNRA already 'predict' the outcomes of our final analysis, in which we intend to concentrate on the three specific medical specialisation (training) positions, we conduct this analysis as planned.

We order the three specialisation positions according to the duration of their training periods, reflecting the opportunity to obtain a higher expected lifetime income (see also Appendix 2).

\section{Effects of competence levels on three types of specialisation positions (ordered)}

With ordinal regression analyses we test the effects of start- and end-level competence on the acquisition of a specialisation position of a longer duration, controlled for gender, age, and relevant years of entry in the labour market again. In this respect, the social medicine in training category is considered the lowest and the hospital specialisations (residency positions in training) the highest category, while general practitioners' training lies in between. Table 6 presents the results. 
Table 6

Estimates of the effects of competence levels at the start and at the end of medical education on obtaining a higher ranked specialisation position based on required further training investment (reflecting expected lifetime income)

\begin{tabular}{|c|c|c|c|c|c|c|}
\hline & \multicolumn{2}{|c|}{ Model 1} & \multicolumn{2}{|c|}{ Model 2} & \multicolumn{2}{|c|}{ Model 3} \\
\hline & estimate & s.e. & estimate & s.e. & estimate & s.e. \\
\hline \multicolumn{7}{|l|}{ Tresholds (a) } \\
\hline General Practitioner & $-2,388^{*}$ & 1,275 & $-2,790^{* *}$ & 1,156 & $-2,677^{* *}$ & 1,321 \\
\hline Hospital Specialisation & $-0,977$ & 1,262 & $-1,378$ & 1,140 & $-1,253$ & 1,307 \\
\hline \multicolumn{7}{|l|}{ Competence level start education } \\
\hline GPA's & 0,189 & 0,117 & & & 0,161 & 0,126 \\
\hline First Progress Test score first year & $-0,030$ & 0,168 & & & $-0,034$ & 0,168 \\
\hline \multicolumn{7}{|l|}{ Competence level end education } \\
\hline \multicolumn{6}{|l|}{ Final Progress Test score in fourth } & 0,123 \\
\hline \multicolumn{6}{|l|}{ Final Skills Test score of fourth } & 0,120 \\
\hline \multicolumn{7}{|l|}{ Control Variables } \\
\hline Male & $0,695^{* * *}$ & 0,252 & $0,610^{* *}$ & 0,253 & $0,657^{* * *}$ & 0,256 \\
\hline Age & $-0,058$ & 0,040 & $-0,072^{*}$ & 0,038 & $-0,066$ & 0,041 \\
\hline Year of entry 1996 & $-0,233$ & 0,503 & $-0,222$ & 0,498 & $-0,294$ & 0,507 \\
\hline Year of entry 1997 & 0,237 & 0,517 & 0,240 & 0,482 & 0,194 & 0,519 \\
\hline Year of entry 1998 & $-0,182$ & 0,496 & $-0,189$ & 0,471 & $-0,236$ & 0,501 \\
\hline Year of entry 1999 & $-0,016$ & 0,525 & $-0,017$ & 0,512 & $-0,043$ & 0,528 \\
\hline \multicolumn{7}{|l|}{ Model Statistics } \\
\hline Number of cases $(n)$ & & 112 & & 112 & & 112 \\
\hline -2 Log Likelihood & & 217,737 & & 217,540 & & 215,846 \\
\hline Model Chi-square & & 14,029 & & 14,226 & & 15,920 \\
\hline df & & 8 & & 8 & & 10 \\
\hline$p$ & & 0.081 & & 0,076 & & 0,102 \\
\hline Link: Probit & & & & & & \\
\hline
\end{tabular}

a The reference category is Social Medicine.

* Significant at $0.10,{ }^{* *}$ significant at 0.05 and ${ }^{* * *}$ significant at 0.01 .

Note 1: Standardized values are used for all competence indicator variables.

Note 2: Year of entry 2000 is the reference category for the 'year of entry' control variables.

As can be seen from table 6, the ordinal regression model is estimated as a probit linked threshold model with three categories. They represent the distances between ordered outcomes for which the exact distances between the categories is unknown, but for which the ordering represents an underlying continuous variable, such as in our study the amount of investment in training (see also Long, 1997; Snijders \& Bosker, 1999). The results can be 
interpreted as follows: being a male enlarges the chances for specialisation positions of a longer duration in all models. The effects are estimated as a part of the distance between the categories (threshold $2-$ threshold 1 ), which is $-2.388-(-0.977)$ ) $=-1.411$ in the first model. When the effect of being male is 0.695 , this is less than a half of the distance of 1.411 . This may be interpreted as the effect of male on the job outcome is on average almost half a higher ranked job category. In the second and third model the effect of gender is related to almost the same amount (almost a half) of a category higher outcome. It must be noted that the chance to obtain a GP in training position is the highest in general. With respect to the start level competence indicators, no effects are found. For the end-level indicators, a positive effect is found for the final Progress Test score. Its effect expects the chance to obtain a 'higher' position to increase for the distance of about only a seventh of a category, when scoring one standard deviation higher on the test. A higher age has a small negative effect to obtain a higher position in the ranked ordering of specialisation positions. However, in the third and final model, only the effect of being a male remains present, and the other effects disappear. Thus, even when ordering only the types of specialisations, no real differentiation of the candidates based on their competence levels is explaining their allocation over the different positions. Gender is the most important factor in explaining the differences.

\section{Summary of results}

Overall, the effects in our regression analyses seem to suggest marginal roles of differential competence acquisition in medical education, and/or a more screening function of medical education for labour market outcomes of physicians. Although the start level indicators of competence predict levels of competence at the end of education (as confirmed in the analysis in Appendix 4), they reveal no further explaining effects for labour market outcomes, not even after controlling for the end level indicators of competence (relation a, i.e. the screening argument can not be confirmed). From the end-level indicators in our models, the final Progress Test scores seem to have some effects (relation b, i.e. the human capital argument is partly confirmed), but when controlling for the start level indicators of competence again, these effects disappear (relation $b$ is not fully confirmed). These are remarkable findings, merely suggesting credit for the Credentialism view. However, considering the already higher levels in scores on all competence indicators for the research subjects, due to selective processes, a more differentiated approach in interpreting the results is needed. Because both levels of competence at the start and at the end of education are higher for the research sample that remains available for our labour market analyses, it can not be denied that education both screens students on their already present competence (students dropping out from the program have lower mean scores for GPA's), as well as that education equips students (referring to acquisition of human capital) with relevant knowledge that affects their labour market entry (the final Progress test reveals effects in the analyses, although the remaining research sample has already higher scores). This is an indication that the labour market outcomes for physicians are merely based on a guaranteed minimum of their competence levels, without further differentiation for good and mediocre students. In this respect, it is in fact remarkable that we still find effects of the final Progress test scores for our already biased research sample, indicating higher final Progress Test scores increase one's chance to obtain a higher ranked specialisation position, and 
differentiate the social medicine in training category from other job categories. The fact that no effects are found from the start level competence indicators, nor from the end level indicators after controlling for the start level indicators, may well be explained in the light of the selection effects instead of by being insignificant in themselves. Without considering the selection processes (bias), these underlying processes of the rather credential function of medical education would not have been visible at all, or not convincing enough.

In the last section of this paper, conclusions will be drawn from the results and considerations for future research will be presented.

\section{Conclusion and Discussion}

\section{What we did}

In this paper, an empirical study has been conducted into the role of medical education for the selection and allocation on the labour market for physicians, a year and a half after graduation. For this purpose, we measured whether medical education really adds to the human capital or competences of students. This type of measurement is scarce in labour market research, but we had such a measurement available in the unique form of Progress Tests scores of medical students during their medical program. However, to separate the effects of actual acquired competence from more general and already present capacities of physicians, we considered the effects of competence levels for physicians at the start and at the end of their medical study separately and controlled for multicollinearity in our data. Successful labour market outcomes have been defined in terms of the chances to obtain a physicians' job, a specialisation position, for obtaining a certain type of medical job, and for the type of specialisation position obtained (sub-sample), ordered by training duration, reflecting further investment in human capital and the expected lifetime income.

\section{What we found}

The results indicate that almost $98,5 \%$ of the physicians in our research sample have found a relevant job; the medical degree therefore seems to 'guarantee' the allocation to relevant medical jobs, which is also confirmed by logistic regression analyses, in which no effects of competence indicators appear. This finding is in line with the Credentials view. However, instead of being irrelevant, the required levels of competences may be of a guaranteed minimum, as illustrated by the selection bias towards higher scores in our research sample, and therefore not visible in a rather undifferentiated outcome.

For the chances to obtain a specialisation position as such, no effects have been found for competence levels either. This is in line with earlier findings (see e.g. Borghans \& Ramaekers, 1993) and may be due to the unimportance of differences in competence levels of candidates again, but can also be explained by a heterogeneous composition of both specialisation and non-specialisation positions.

Distinguishing the different types of jobs physicians can obtain, and analysing whether competence levels have differentiating value for obtaining these jobs, reveals some more information. For the social medicine positions it can be said that the positive effect of being female is most profound and characteristic, compared to hospital specialisation positions. 
The question is however, to what extent the preferences of women as a group for social medicine are the underlying reason for the gender effect, or whether selection processes and structural constraints for different job categories (such as some hospital specialisations) are the reason (see for example Gjerberg, 2002).

However, controlled for gender, age and year of entry in the labour market, the actual acquired competence in education seems to differentiate the social medicine in training positions from the hospital specialists in training, and therefore in fact from the GP's in training, the residents not in training, and PhD's as well (human capital argument). This effect disappears again when controlling as well for the start level indicators of competence. This suggests that the specific competence acquired in education is not differentiating enough, compared to the generic component included in the effect, to reveal effects when controlling for the already present competence at the start of the study. In all, after having passed the final medical qualifying examination, competence levels as measured in this study seem not to play an important role in the selection and allocation of physicians on the labour market. The same accounts for the findings of our last analysis, in which three specific medical training positions have been considered separately, by ordering them according to their training period, also reflecting expected lifetime income. This means we cannot find firm evidence for a screening or human capital mechanism in the selection and allocation of physicians on the medical labour market, or, in other words, no screening or human capital acquisitive role of their medical education.

The measurement properties of the Progress Test seem however to reveal more predictive information than the Skills Test, possibly related to the different aspects of competence that are measured by these different tests. It is suggested that scoring higher on the Progress Test is related to learning or study style aspects of students that are considered to be desirable for academic students (see e.g. Van Berkel et al., 1995; Verhoeven, 2003).

Much effort is currently put in research into the relationships between (cognitive) ability, personality, learning style and work performance (see e.g., Furnham et al., 1999; Austin et al., 2002; Zhang, 2003) to detect the relevant aspects and their dynamic behaviour. To draw more conclusions in this respect, we would need to extent the study with measurements of generic competences, such as learning style data.

\section{What we conclude}

Overall, our results indicate the importance of mainly the credential role of medical education for the selection and allocation of physicians on the labour market. However, selection of students takes already place during the medical program and passing the final medical qualifying examination within a limited range of time (10-12 years, while medical study takes numerical 6 years). Therefore the more qualifying and screening role of medical education seem merely of importance to garantee a minimum quality of the physicians before entering the labour market. However, taking the already higher scores on both start and end level competence indicators for the responding subjects on the labour market survey into account, this conclusion must be handled with care; it may be possible that the importance of differences in competence is not visible in our analyses, because the information of many (238 out of 546 ) graduated physicians is not available due to non-response on the labour market survey. 


\section{Shortcomings and avenues for future research}

Since we only include short-term labour market outcomes, an important question is what effects medical education will have on the longer-term labour market outcomes of physicians. Will the short-term human capital effects continue to exist, or will there be different outcomes with respect to the value of education? Future research into the longer-term labour market outcomes is an interesting and necessary road to follow, also considering the changing career paths of physicians (Goldacre \& Lambert, 2000). Since criteria for labour market success may also be linked to the quality of the performance of medical doctors in their work, this would be another or related route for future research.

The promising role of Progress Test scores in measuring acquired competence during education and its predictive value for labour market outcome indicators should be further tested. What is the relation with generic skills, such as learning styles, what does it mean for later labour market functioning? What is the predictive value of the Progress test for later clinical performances of doctors?

\section{Final conclusion}

For now we end with the notion that a first attempt has been made to empirically separate the possible effects of education, as Sørenson (1994) already pled for. The availability of the unique Progress Test measurements, in combination with the separate indications of the start- and end-level competence of students in their study, informed us fairly well about what role(s) the academic medical study plays in the first selection and allocation of physicians on the labour market. In this respect, the presence of three possible mechanisms have been considered empirically; the value of the medical degree, referring to credentialism; the start level competence indications, such as GPA's, referring to a screening mechanism; and the end level competence indications, such as the Progress Test scores and the Skills Test scores, referring to a human capital mechanism. By doing this, a step forward has been made to develop theory concerning the role of education for labour market outcomes, not only for physicians but for other graduates as well. 


\section{References}

Atkinson, R. L., Atkinson, R.C., Smith, E.E \& Hilgard, E.R. (1987) Introduction to Psychology (Orlando, Florida, U.S.A., Harcourt Brace Jovanovich Publishers).

Austin, E. J., Deary, I.J., Whiteman, M.C., Fowkes, F.G.R., Pedersen, N.L., Rabbitt, P., Bent, N. \& McInnes, L. (2002) Relationships between ability and personality: does intelligence contribute positively to personal and social adjustment?, Personality and Individual Differences, 32, pp. 13911411.

Baker, E. L. (2001) Testing and Assessment: A Progress Report., Educational Assessment, 7(1), pp. 1-12.

Becker, G. S. (1983) Human Capital: A Theoretical and Empirical Analysis, with special reference to Education (New York, National Bureau of Economic and Social Research).

Berg, van den, G. J., Holm, A. \& Ours, van, J.C. (2002) Do stepping-stone jobs exist? Early career paths in the medical profession., Journal of Population Economics, 15, pp. 647-665.

Berkel, H. J. M. van, Nuy, H.J.P. \& Geerligs, T. (1995) The influence of progress tests and block tests on study behaviour., Instructional Science, 22, pp. 317-333.

Borghans, L. \& Ramaekers, G.W.M (1993) De doorstroom van limburgse basisartsen naar medische beroepsopleidingen (Maastricht, Research Center for Education and the Labour Market).

Boshuizen, H. P. A. \& Schmidt, H.G. (2000) Development of clinical reasoning expertise; implications for teaching, in: J. J. Higgs \& M. Jones (Eds.) Clinical reasoning in the health professions. second completely revised edition (Oxford, Butterworth-Heineman).

Cawley, J., Heckman, J. \& Vytlacil, E. (2001) Three observations on wages and measured cognitive ability., Labour Economics, 8(4), pp. 419-442.

Collins, R. (1979) The Credential Society; an historical sociology of education and stratification (New York, Academic Press).

Ethington, C. A., Thomas, S.L. \& Pike, G.R. (2002) Back to the Basics; Regression as it schould be, in: J. C. Smart \& W. G. Tierney (Eds.) Higher Education: Handbook of Theory and Research (Dordrecht, Kluwer Academic Publishers).

Furnham, A., Jackson, C.J. \& Miller, T. (1999) Personality, learning style and work performance., Personality and Individual Differences, 27, pp. 1113-1122.

Gjerberg, E. (2002) Gender similarities in doctors' preferences - and gender differences in final specialisation., Social Science \& Medicine, 54, pp. 591-605.

Glaser, R. (1990) Towards New Models for Assessment., International Journal of Educational Research, 14, pp. 475-483.

Goldacre, M. J. L. \& Lambert, T.W. (2000) Stability and change in career choices of junior doctors: postal questionnaire surveys of the United Kingdom qualifiers of 1993., Medical Education ${ }_{2} 34$, pp. 700-707.

Irandoust, M. \& Karlsson, N. (2002) Impact of Preferences, Curriculum and Learning Strategies on Academic Success., Education Economics, 10(1), pp. 41-47.

Lindblom-Ylänne, S. \& Lonka, K. (2001) Students' Perceptions of Assessment Practices in a Traditional Medical Curriculum., Advances in Health Sciences Education, 6, pp.121-140.

Long, J. S. (1997) Regression Models for Categorical and Limited Dependent Variables (Thousand Oaks, Sage Publications Inc.).

Luijk, S.van, Wolfhagen, H.A.P., \& de Grave, W.S. (1990) Het voortijdig beëindigen van de studie Geneeskunde aan de Rijksuniversiteit Limburg. Interne rapportage van de vakgroep Onderwijsontwikkeling \& Onderwijsresearch (Maastricht, Rijksuniversiteit Limburg).

McNabb, R. (1987) Labour Market Theories and Education, in: Psacharopoulos, G. (Ed.) Economics of Education: Research and Studies (Oxford, Pergamon Press).

Norcini, J.J. \& Lipner, R.S. (2000) The relationship between the nature of practice and performance on a cognitive examination., Academic Medicine, 75 (10 Suppl), pp. 68-70. 
Norman, G. R. (1988) Problem-solving skills, solving problems and problem-based learning., Medical Education, 22, pp. 279-286.

Quinn, R. P. \& Price, J. (1998) The Demand for Medical Education: an Augmented Human Capital Approach., Economics of Education Review, 17(3), pp. 337-347.

Schmidt, H. G., Norman, G.R. \& Boshuizen, H.P.A. (1990) A cognitive perspective on medical expertise: theory and implications., Academic Medicine, 65, pp. 611-621.

Semeijn, J.H. \& Velden, van der, R.K.W. (2002) Aspects of Learning style and labour market entry; an explorative study, in: Johannessen, T.A., Pedersen, A. \& Petersen, K. (Eds.) Educational Innovation in Economics and Business Education V. Teaching Today the Knowledge of Tomorrow (Dordrecht, Kluwer Academic Publishers).

Slotnick, H. B. (2001) How Doctors learn: Education and Learning across the Medical-school-topractice Trajectory., Academic Medicine, 76(10), pp. 1013-1026.

Snijders, T. B. \& Bosker, R. (1999) Multilevel Analysis. An introduction to basic and advanced multilevel modelling (Trowbridge, Wiltshire, The Cromwell Press Ltd.).

Sørenson, A. B. (1994) Opportunity and Training Effects on Careers (Network on Transitions in Youth).

Spence, A. M. (1974) Market Signalling: Informational Transfer in Hiring and Related Screening Processes (Cambridge, Harvard University Press).

Tamblyn, R., Abrahamowicz, M., Brailovsky, C., Grand'Maison, P., Lescop, J., Norcini, J., Girard, N. \& Haggerty, J. (1998) Association between licensing examination scores and resource use and quality of care in primary care practice., Journal of the Academic Medical Association, 16, 280 (11), pp. 989-996.

Thornton, J. (2000) Physician choice of medical specialty: do economic incentives matter?, Applied Economics, 32, pp. 1419-1428.

Thurow, L. C. (1975) Generating Inequality (New York, MacMillan).

Perquin, M.L.F. (1999) Studiestakersenquete studiejaar 1997/1998. Interne rapportage van de capaciteitsgroep Onderwijsontwikkeling \& Onderwijsresearch, t.b.v. de examencommissie (Maastricht, Universiteit Maastricht).

Velden, van der, R.K.W. \& Wieling, M.H. (1994) De arbeidskansen per opleiding, in:

Scholten, H. \& De Groot, S.C. (Eds). Arbeidsmarkt en Sociale Zekerheid, Beleid en

Beweging (Delft, Eburon).

Verhoeven, B.H. (2003) Progress Testing: The utility of an assessment concept (Doctoral Dissertation, Maastricht University).

Vleuten, van der, C. P. M., Verwijnen, G.M. \& Wijnen, W.H.F.W. (1996) Fifteen years of experience with progress testing in a problem based learning curriculum., Medical Teacher, 18(2), pp. 103109.

Weiss, A. (1995) Human Capital vs Signalling Explanations of Wages, Journal of Economic Perspectives, 9(4), pp. 133-154.

Zang, L. (2003) Does the big five predict learning approaches?, Personality and Individual Differences, 34, pp. 1431-1446. 


\section{Appendix 1}

The value of Progress Test scores in measuring actual learning accumulation in relevant competences in medical education

The Progress Test in medical education can best be conceived of as a final examination: a comprehensive examination reflecting the (cognitive) end-objectives of the curriculum (Van der Vleuten et al., 1996). We now literally recall a part of the text in this article by Van der Vleuten et al. (1996): "Each Progress Test consists of approximately 250 (multiple) true/false questions stratified in categories based on the International Classification of Diseases (ICD). It samples knowledge across all disciplines and content areas in medicine relevant for the medical degree. Four times per year the progress test is given to all students in the curriculum, regardless of their class. For each occasion a newly constructed version is prepared. A single test question may be answered with either true or false, or with an 'I do not know' option (the question mark). The latter option is not penalized or rewarded. A correct answer is rewarded with one mark while an incorrect answer is given a negative mark. To discourage guessing a total test score is expressed as the number of correct answers minus the number of incorrect answers. To allow comparison across tests, scores are expressed on a percentage scale. The freshmen year students are not able to answer as many questions as the second-year students, who are not able to answer as many as the third-year students and so on..."

Measurement with the Progress Test reveals satisfactory reliability coefficients (across years usually alphas above 0.95 , within years alphas between $0.70-0.80$ ) and test construction is highly standardized. Test difficulty variations remain present though. Validity in measuring the development in relevant medical competence as an indicator for the actual learning process that takes place in education seems although satisfactory, as we argue as follows:

The measurement is congruent with the educational findings with respect to competence development of medical students and physicians; the knowledge component is crucial for this process. The development of medical expertise is considered the same as learning to solve problems within the medical knowledge domain (Boshuizen \& Schmidt, 2000). However, the knowledge domain has to be solid enough to facilitate the expertise development process. This implies the explicit importance of knowledge and the acquisition of this knowledge during education. In fact, two types of knowledge are relevant for physicians; conceptual and experiential knowledge (Schmidt et al., 1990). The conceptual type is merely acquired during formal education, and experiential knowledge is acquired based on the conceptual knowledge, during work (Norman, 1988).

Based on the findings concerning medical knowledge, we assume the specific conceptual knowledge acquisition in education to be of major importance to the competence development process in education we like to measure. We assume the growth in conceptual medical knowledge to be captured and monitored satisfactory with the 'Progress Test'.

Although the medical study officially takes six years, the last two years are reserved for the so-called clinical clerkships. These clerkships periods can bias the Progress Test scores in the fifth and sixth year in two ways: in the first place the learning environment has extremely changed, which can affect the scores on the tests, and in the second place, not every student has to pass the last tests for graduation, so only the less well scoring students will 
have to do these last tests. We therefore consider the final Progress Test score in the fourth year as the end-level indicator of competence developed during education.

To underline the value of the final Progress Test scores of the fourth year in measuring the attained level of medical competence and the difference in this respect with the more traditional study results in our sample, we refer to figure 1-3.

Progress Tests

Mean \% correct minus false answers

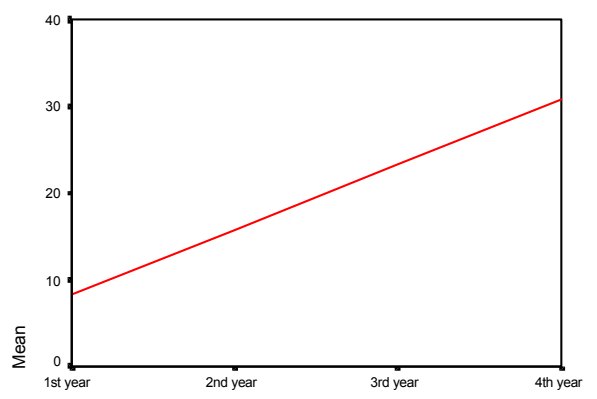

Figure 1: grow curve mean sample scores year 1-4 for Progress tests

Block Tests

Mean \% correct minus false answers

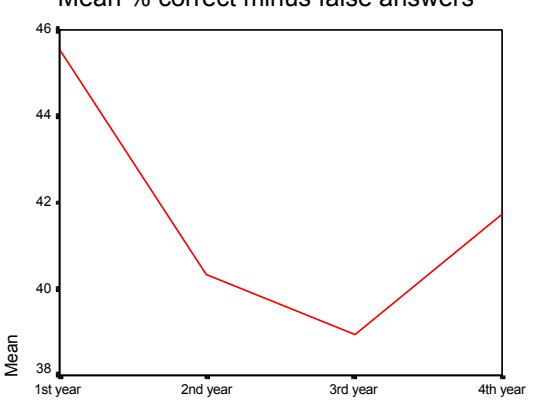

Figure 2: grow curve mean sample scores year 1-4 for Block Tests

Skills Tests

Attained level of correct answers (\%)

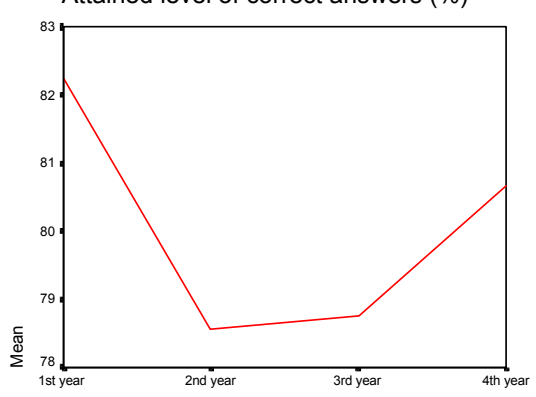

Figure 3: grow curve mean sample scores year 1-4 for Skills Tests

The Progress test scores from our sample reveal comparable findings with respect to growth curves on the cohort level, such as presented in the study of Van der Vleuten et al. (1996). In addition, no bias was found in growth between the cases in our research sample (restricted by the availability of relevant labour market information) and our total data set of students that had taken the Progress tests during the relevant cohort periods. 


\section{Appendix 2}

\section{Argumentation for indicators of labour market success for physicians}

Labour market outcomes for individuals can be considered in terms of chances for a job and the quality of the job (Van der Velden \& Wieling, 1994; Semeijn \& Van der Velden, 2002). However, for physicians these labour market outcome indicators do not reveal as much information as for other graduates, such as economists. Their chances of obtaining a medical job are extremely high because only physicians can attain these jobs and labour market demand and supply are highly controlled by institutional regulations, for example by a maximum number of specialists that is allowed to be trained, and the numeri fixi for the number of students that is allowed to start the medical academic program in the first place. The salaries in specialisation positions are highly regulated as well, and therefore not very informative either. The chances for attaining a specialisation position seem relevant. It seems more successful to obtain a specialisation position faster. However, it can be a wellconsidered choice to gain medical experience in a non-specialisation position first, and wait for a better or more preferred specialisation position a little later in the career. This leads to the situation that both physicians in specialisation and non-specialisation positions, a year and a half after graduation, constitute heterogeneous groups. This heterogeneity may be a reason why earlier research did not find any further explaining factors for the chances to obtain a specialisation position than the medical degree as such. This means that the group who did not yet obtain a specialisation position rather shortly after graduation, consists both of graduates who are not able to get or want such a position and of graduates who are well qualified and are still waiting in the queue. Similarly, the group of specialists in training is heterogeneous as well, consisting of positions that require extensive training in highly specialized medical area's (hospital specialisations) and positions that require much less further training within a broader field of practice (social medicine). Since both specialisation and non-specialisation positions are heterogeneous, we will distinguish the most important types of specialisation and non-specialisation positions as a relevant labour market outcome in terms of the type of job physicians obtain. And, of course, we will first test our assumption with respect to the attainment of a specialisation position as such.

In addition, specialisation positions themselves can be ranked according to the duration of the training period. Hospital specialisations take usually 5 to 7 years of training, while general practitioners' training takes 3 years, and the social medicine specialisations 2-2,5 years. In economic terms, the highest specialisation type in ranking requires the largest investment in human capital and leads to the largest returns in terms of lifetime income. It is common knowledge that hospital specialists will earn the most, during their entire career, whereas general practitioners earn much less, and social physicians will earn the least, after they have completed training. The duration of the training periods therefore reflects the individuals' opportunity to obtain a higher lifetime income. Although the stability of obtained specialisation positions shortly after graduation may be fairly low, considering the further careers of physicians (see for example Gjerberg, 2002; Goldacre \& Lambert, 2000), the analysis of (human capital) factors affecting the attainment of a higher ranked position shortly after graduation is of interesting value on its own. Starting positions after graduation are influential for later labour market outcomes (see e.g., Van den Berg et al., 2002), and 
although physicians do not choose their specialisation solely based on the expected income, economic incentives are found to play a significant role in their choice processes (Thornton, 2000; Quinn \& Price, 1998). 


\section{Appendix 3}

\section{Selection bias in competence levels for a research sample of physicians}

Table I

Selection bias in physicians' scores in the research sample

Mean group 1 Sd group 1 Mean group 0 Sd gro

1) Availability of end-level competence indicators (dummy)

$N=573$

GPA's $\left(0.408^{* * *} / 0.133\right)$

First Progress Test score in 1 st year $\left(0.831^{*} / 0.467\right)$

\section{2) Graduated by 2000 (dummy)}

GPA's $\left(-0.407^{* *} / 0.196\right)$

First Progress Test score in 1st year $(-0.124 / 0.744)$

Final Progress Test score 4th year $\left(0.471^{* *} / 0.224\right)$

Skills Test score in 4 th year $(0.161 / 0.189)$

\section{3) Labour market response (dummy)}

\section{GPA's $(0.173 * / 0.097)$}

First Progress Test score in 1 st year $(0.224 / 0.331)$

Final Progress Test score 4th year $(0.117 / 0.100)$

Skills Test score in 4 th year $\left(0.298^{\star * *} / 0.099\right)$$$
6,83
$$$$
4,50
$$$$
N=546
$$$$
6,82
$$$$
4,51
$$$$
32,89
$$$$
80,49
$$$$
N=308
$$$$
6,89
$$$$
4,67
$$$$
33,72
$$$$
81,68
$$

d group

$N=94$

6,59

3,73

0,54

3,07

3,358

2,160

0,001

$N=27$

6,99

4,49

29,97

78,03

0,80

3,10

$-1,318$

0,029

1,832

10,26

1,149

0,977

$\mathbf{0 , 0 6 7}$

0,251

$N=238$

6,72

4,30

0,59

3,093

1,312

31,81

3,24

2,794

0,002

78,95

4,052

0,190

0,005

0,000

Note 1: group 1 refers to the available, remaining cases; group 0 refers to the cases that drop out of the sample in the sequential step in the selection process.

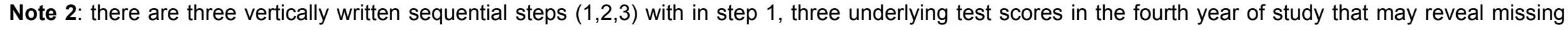

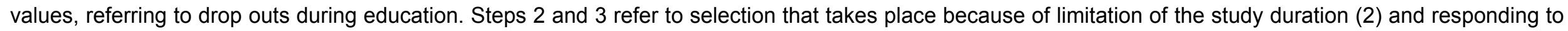
the labour market survey (3).

Note 3: the parameter estimates of the logistic regression analyses are presented between the parentheses, with * significant at the 0.1 level, ${ }^{* *}$ at the 0.05 level, and ${ }^{* * *}$ at the 0.01 level. 


\section{Appendix 4}

Effects of competence levels at the start on competence levels at the end of medical education

The effects of start-level competence indicators on end-level competence indicators are tested by linear regression analyses; for the Progress Test scores at the end of the fourth year, and for the Skills Test scores of the fourth year. The results are presented in table I.

Table II

Regression estimates of the effects of competence indicators at the start of medical education on competence indicators at the end of medical education

\begin{tabular}{|c|c|c|c|c|}
\hline & \multicolumn{2}{|c|}{$\begin{array}{l}\text { Final Progress Test } \\
\text { fourth year }\end{array}$} & \multicolumn{2}{|c|}{$\begin{array}{l}\text { Skills Test } \\
\text { fourth year }\end{array}$} \\
\hline & $B$ & s.e. & $B$ & s.e. \\
\hline Constant & $0,261^{* * *}$ & 0,075 & $0,129^{*}$ & 0,078 \\
\hline \multicolumn{5}{|l|}{$\begin{array}{l}\text { Competence level start medical } \\
\text { education }\end{array}$} \\
\hline GPA's & $0,315^{\star * *}$ & 0,039 & $0,196^{* * *}$ & 0,041 \\
\hline First Progress Test score 1st year & $0,415^{\star \star \star}$ & 0,144 & 0,189 & 0,149 \\
\hline \multicolumn{5}{|l|}{ Model Statistics } \\
\hline Number of cases $(n)$ & & 573 & & 573 \\
\hline Adj.R2 & & 0,120 & & 0,041 \\
\hline $\mathrm{F}$ & & 40,135 & & 13,343 \\
\hline$P$ & & 0,000 & & 0,000 \\
\hline
\end{tabular}

Note: standardized values are used for all variables

${ }^{*}$ significant at $0.10,{ }^{* *}$ significant at 0.05 and ${ }^{* * *}$ significant at 0.01 .

As can be seen from table I, higher GPA's have a positive effect on both competence indicators at the end of education. Higher first Progress Test scores of the first year have a positive effect on the final Progress Test scores of the fourth year, but not on the Skills Test scores of the fourth year. Although the type of instrument should be taken into account, our first assumed relation seems confirmed; the competence level just before or at the start of medical education affects the level of competence at the end of medical education. This means: differentiation in the competence levels at the end of medical education is partly predicted by the differences in start levels of the students. And apparently, the types of competence that are measured by Progress tests and Skills tests are much more different than both of them differ from the competence that is already measured by GPA's. This is suggested by the descriptives (correlations) in table 1 of the results in the paper as well. 